\title{
Demystified...
}

\section{Comparative genomic hybridisation}

M M Weiss, M A J A Hermsen, G A Meijer, N C T van Grieken, J P A Baak, E J Kuipers, P J van Diest

Department of University Hospital, 1007 MB Amsterdam, The Netherlands

$M$ M Weiss

N C T van Grieken

E J Kuipers

Department of Pathology, Free University Hospital, PO Box 7057, 1007 MB Amsterdam, The Netherlands M A J A Hermsen G A Meijer J P A Baak

P J van Diest Dr van Diest. email: pj.vandiest@azvu.n

Accepted for publication 1 April 1999 Gastroenterology, Free

Correspondence to:

\begin{abstract}
Comparative genomic hybridisation (CGH) is a technique that permits the detection of chromosomal copy number changes without the need for cell culturing. It provides a global overview of chromosomal gains and losses throughout the whole genome of a tumour. Tumour DNA is labelled with a green fluorochrome, which is subsequently mixed $(1: 1)$ with red labelled normal DNA and hybridised to normal human metaphase preparations. The green and red labelled DNA fragments compete for hybridisation to their locus of origin on the chromosomes. The green to red fluorescence ratio measured along the chromosomal axis represents loss or gain of genetic material in the tumour at that specific locus. In addition to a fluorescence microscope, the technique requires a computer with dedicated image analysis software to perform the analysis. This review aims to provide a detailed discussion of the CGH technique, and to provide a protocol with an emphasis on crucial steps.

(F Clin Pathol: Mol Pathol 1999;52:243-251)
\end{abstract}

Keywords: comparative genomic hybridisation; methodology; protocol; paraffin wax embedded material

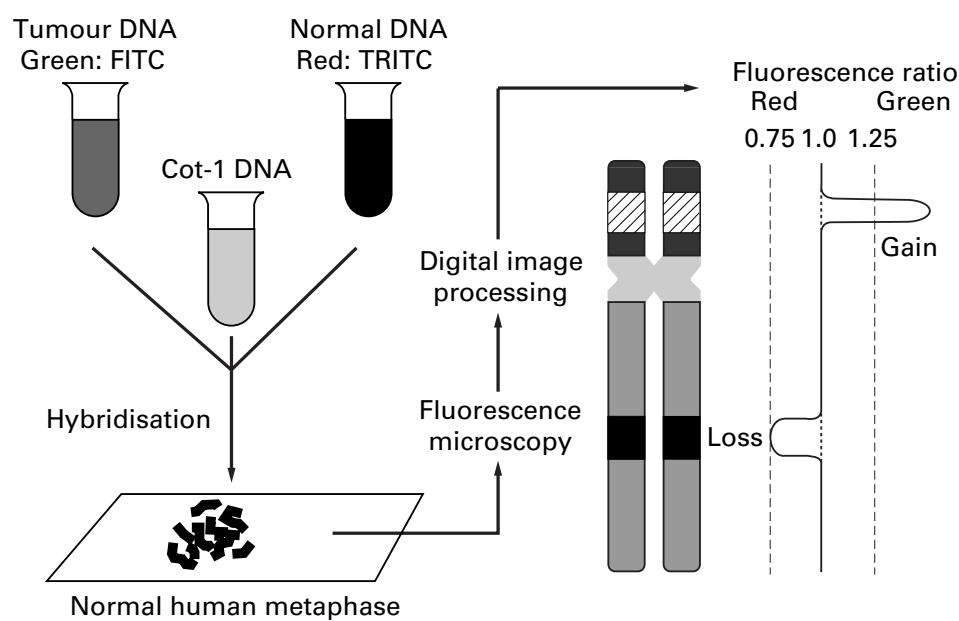

Figure 1 Principle of comparative genomic hybridisation (CGH). Schematic overview of the CGH technique. Tumour and reference DNA are labelled with a green and red fluorochrome, respectively, and hybridised to normal metaphase spreads. Images of the fluorescent signals are captured and the green to red signal ratios are quantified digitally for each chromosomal locus along the chromosomal axis.
Comparative genomic hybridisation $(\mathrm{CGH})$ is a technique that permits the detection of chromosomal copy number changes without the need for cell culturing. It gives a global overview of chromosomal gains and losses throughout the whole genome of a tumour. Thus, CGH is a relatively fast screening technique that can point at specific chromosomal regions that might play a role in the pathogenesis or progression of tumours. Guided by CGH results, more specific molecular biological techniques (such as fluorescence in situ hybridisation, loss of heterozygosity analysis, and sequencing) can be used to identify oncogenes and/or tumour suppressor genes in these regions.

Kallioniemi et $a l$ at the University of California, San Francisco were the first to report $\mathrm{CGH}$ as a new chromosome analysis technique in 1992, ${ }^{1}$ shortly followed by du Manoir et al. ${ }^{2}$ In short, tumour DNA is labelled with a green fluorochrome, mixed (1:1) with red labelled normal DNA, and hybridised to normal human metaphase preparations. The normal reference DNA and the metaphases are obtained from a healthy volunteer and do not need to be from the patient. The green and red labelled DNA fragments compete for hybridisation to their locus of origin on the chromosomes. The green to red fluorescence ratio measured along the chromosomal axis represents loss (ratio $<1$ ) or gain (ratio $>1$ ) of genetic material in the tumour at that specific locus (figs 1 and 2). In addition to fluorescence

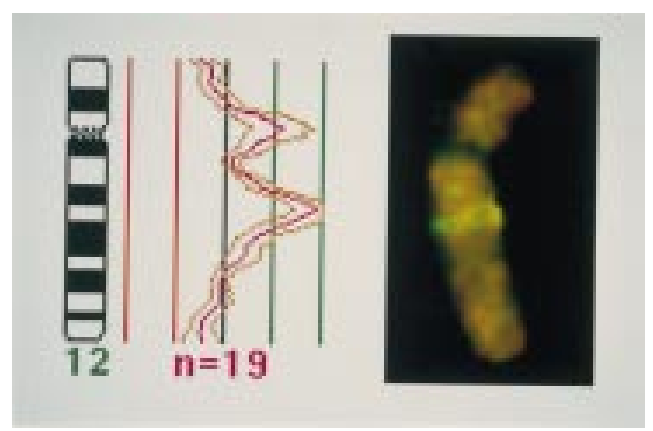

Figure 2 High level gain on the long arm of chromosome 12. The clear green band shows the high level gain or amplification on the long arm of chromosome 12 in a carcinosarcoma of the nasopharynx (chromosomal band 12q15). In addition, the comparative genomic hybridisation $(C G H)$ profile displays a green to red ratio $>>1$. Because of suboptimal blocking of repetitive DNA sequences in the profile, another peak appeared at the site of the centromere, which was interpreted as an artefact and neglected when interpreting $\mathrm{CGH}$ results. 


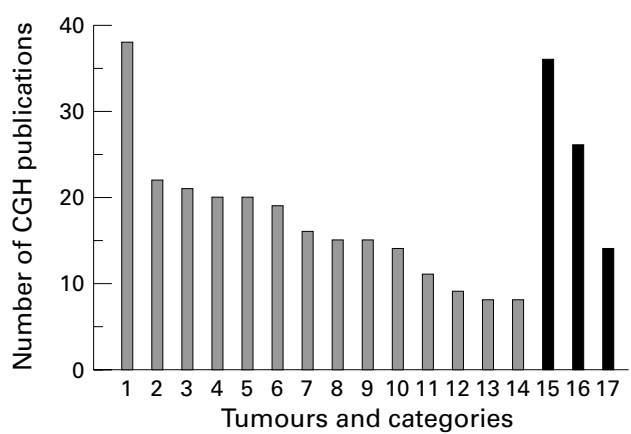

Figure 3 Diversity of tumours analysed by comparative genomic hybridisation (CGH) and types of reports (1992-8). Categories are: (1) neurological tumours; (2) tumours of the male genital tract; (3) tumours of the urinary tract; (4) breast cancer; (5) haematological diseases; (6) tumours of the digestive tract; (7) lung cancer; (8) tumours of the female genital tract; (9) soft tissue tumours; (10) lymphomas; (11) oral tumours; (12) bone cancer; (13) neuroendocrinal tumours; (14) skin cancer; (15) technical reports; (16) reviews; (17) other types of report.

microscopy, the technique requires dedicated computer software for the analysis of results. Initially, it appeared to be rather difficult to perform the technique in other, less specialised laboratories, and it was only after the publication of an article reviewing the method in more detail, and after the necessary software became commercially available, that CGH became more accessible. ${ }^{4}$ Because no cell culturing is required for $\mathrm{CGH}$, this technique has enabled tremendous progress in the analysis of chromosomal changes in solid tumours. Applications of $\mathrm{CGH}$ in cancer research include screening of tumours for genetic aberrations, ${ }^{5-18}$ searching for genes involved in the carcinogenesis of particular subsets of cancers, ${ }^{19}$ analysing tumours in experimental models to obtain an insight into tumour progression, ${ }^{20}$ diagnostic classification, ${ }^{19}$ and prognosis assessment. ${ }^{21}$ At present, CGH is performed in a growing number of laboratories and a wide variety of tumours have been analysed (fig 3). Apart from these oncological applications, CGH analysis has also been used to study chromosomal aberrations in fetal and neonatal genomes. ${ }^{22-24}$

Until now, over 300 articles on CGH have been published by research groups from several countries, including reviews ${ }^{25-27}$ and technical papers $^{28-45}$ (fig 4). This boom is caused mainly by the reduced demands on the material used for CGH. It has become possible to use archival formalin fixed and paraffin wax embedded material, whereas initially only DNA from

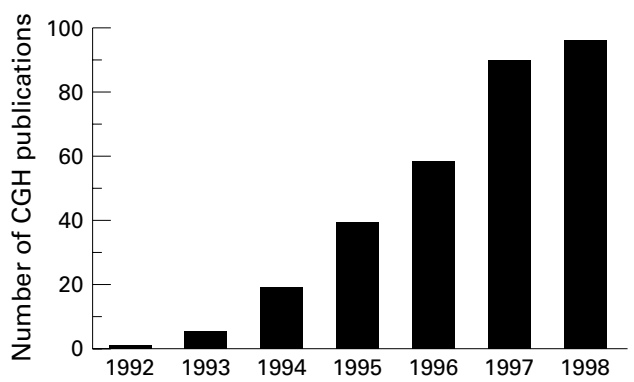

Figure 4 Number of comparative genomic hybridisation (CGH) publications from 1992 to 1998. fresh and frozen tumours and material from cell lines could be used. In addition, by using techniques such as microdissection and degenerate oligonucleotide primed polymerase chain reaction (DOP-PCR), CGH became applicable to smaller lesions. However, the high number of technical reports indicates that $\mathrm{CGH}$ is still viewed as a relatively difficult method. Therefore, we aim to provide a detailed discussion of the $\mathrm{CGH}$ technique, and to provide a protocol with an emphasis on crucial steps.

\section{Sensitivity and limitations}

$\mathrm{CGH}$ is a relatively time consuming and difficult technique with a number of limitations. It cannot detect structural chromosomal aberrations without copy number changes, such as balanced chromosomal translocations, inversions, or ring chromosomes, and it does not yield information in the context of tissue architecture. CGH detects gains and losses relative to the ploidy level. It also has the disadvantage of being less sensitive than PCR based methods in detecting deletions. CGH results are not linearly distributed. Theoretically, the loss or gain of one copy of a certain chromosome in a diploid genome should result in a fluorescence ratio of 0.5 or 1.5 . However, in experiments comparing male and female DNA, where the fluorescence ratio for the $\mathrm{X}$ chromosome should be 0.5 or 2.0, these ratios are never found in practice.

The sensitivity of CGH can be hampered by contamination of tumour material with normal cells, which will be explained in detail elsewhere in this article. Furthermore, the sensitivity of CGH depends on the level and size of the copy number changes. Based on simulation experiments, a copy number increase of $50 \%$ should be detectable if the region is 2 megabase pairs $(\mathrm{Mb})$ or larger, and an amplified region (amplicon) of 250 kilobase pairs (kb) would need a $400 \%$ copy number increase. ${ }^{46}$ The lower limit of detection is determined by the product of the excess copy number and the size of the amplified region. When the deletion is $100 \%$ (no copies present), a resolution of 1-2 $\mathrm{Mb}$ can be achieved. ${ }^{43}$ Based on CGH experiments, the crucial detection size was estimated to be in the range of $10-20 \mathrm{Mb}^{3}{ }^{32} 47$

\section{Description of the protocol and problem} areas of CGH

METAPHASE SLIDE PREPARATION

Metaphase chromosomes are prepared according to standard protocols using phytohaemagglutinin stimulated peripheral blood lymphocytes from a karyotypically normal man or woman. Because women have two X chromosomes and the $\mathrm{Y}$ chromosome does not contain much genetic information, it is preferable to use metaphase spreads from women. High quality metaphase preparations for $\mathrm{CGH}$ should ideally have little cytoplasm (too much cytoplasm causes high background levels and may prevent optimal denaturation), minimal overlapping of the chromosomes (overlapping chromosomes need to be excluded from CGH analysis), and low cell density paired with a 
high mitotic index. In addition, the chromosomes should be of adequate length (400-550 bands) and not contain separated chromatids. Finally, for good banding strength, chromosomes should appear dark, not shiny, when looking through a phase contrast microscope. ${ }^{36}$

In short, $1 \mathrm{ml}$ of heparinised blood is added to $10 \mathrm{ml} \mathrm{Ham} \mathrm{F10} \mathrm{culture} \mathrm{medium} \mathrm{(Gibco}$ BRL, Breda, Netherlands) containing fetal calf serum $(10 \%)$, L-glutamine $(1 \%)$, penicilin and streptomycin $(1 \%)$, and phytohemagglutinin $\left(1.5 \%\right.$ in distilled water) and incubated at $37^{\circ} \mathrm{C}$ in an atmosphere of $5 \% \mathrm{CO}_{2}$ for 72 hours. Cells are arrested in mitosis by the addition of colchicine to a final concentration of $0.01 \mu \mathrm{g} / \mathrm{ml}$, harvested, treated with hypotonic $\mathrm{KCl}$ $(0.075 \mathrm{M})$ and fixed in 3:1 methanol/acetic acid. A crucial step in the procedure is the dropping of the fixed cell solution on to the slides. The success of this step is dependent on many factors (such as weather conditions, cell suspension quality, and laboratory conditions), but in our hands it is best to drop the cell suspension from a distance of $\sim 30 \mathrm{~cm}$ on to ethanol cleaned slides. Usually, one drop of the cell suspension results in a sufficient number of metaphase spreads for one $\mathrm{CGH}$ experiment. Optimal conditions are a room temperature of $24^{\circ} \mathrm{C}$ and a relative humidity of $60-70 \%$. The slides should be evaluated with a phase contrast microscope. If large amounts of residual cytoplasm are still visible on the slides, the fixation step (3:1 methanol/acetic acid) should be repeated a few times. In addition, a postfixation step-dropping 3:1 methanol/ acetic acid on to a vertically positioned slidemight be helpful in removing cytoplasm. Slides are air dried ("aged") overnight at room temperature and stored at $-20^{\circ} \mathrm{C}$ in groups of four, in the presence of either silica beads or nitrogen to keep them dry. It is important to test several batches of metaphase slides from different donors when setting up CGH experiments, because their behaviour in hybridisation can be variable (fig 5). Alternatively, fully pre-

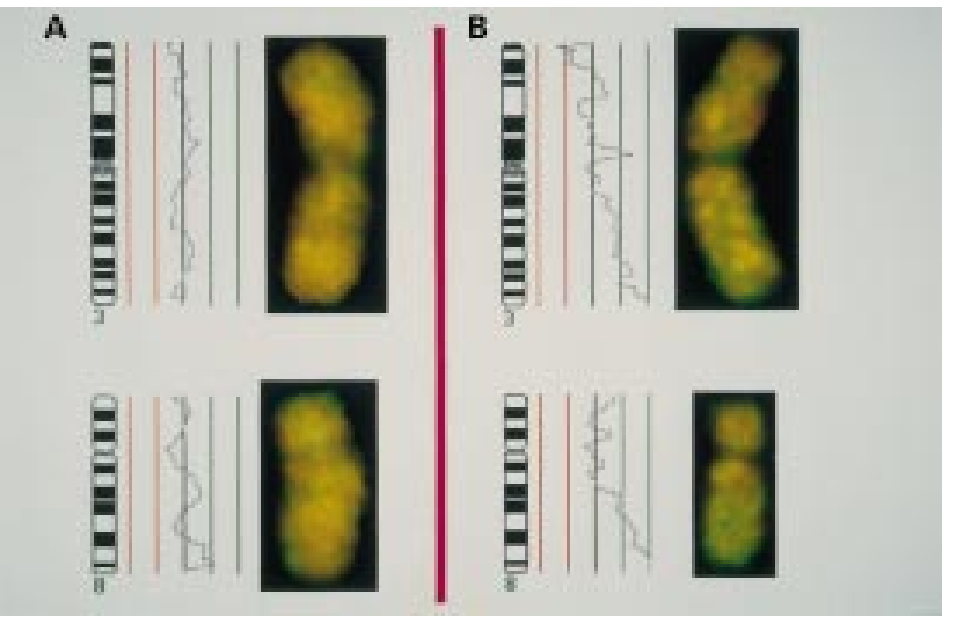

Figure 5 Effect on comparative genomic hybridisation (CGH) results of differences in blocking efficiency between metaphases of different individuals. Metaphase slides of lymphocyte suspensions of two healthy individuals were prepared using standard procedures. On these metaphases, CGH experiments of the same tumour versus normal DNA was performed with the same amount of Cot-1 DNA. Blocking efficiency differed between chromosomes from different individuals $(A v B)$ and insufficient blocking (individual $A$ ) caused repression of the amplitude of the green to red ratio. pared metaphase slides are commercially available (Vysis, Downers Grove, Illinois, USA; catalogue number: 30-806010). However, these slides still need to be tested before use, and the quality is not necessarily better than that of slides produced in house, as described above.

DNA ISOLATION FROM TUMOUR TISSUE

The quality of DNA is a very important issue when performing CGH. DNA extracted from fresh or frozen tissue is usually of high molecular size (not degraded) and will be of the best quality for labelling purposes. However, when using formalin fixed, paraffin wax embedded tissue, the extracted DNA will be partly degraded (300-20000 bp) and crosslinked. The quality of DNA from paraffin wax embedded tissues depends greatly on the $\mathrm{pH}$ of the formalin fixative, and on the duration of fixation; thus, neutral buffered formalin ( $\mathrm{pH} \mathrm{7.0)}$ and fixation for no longer that 24 hours usually preserves DNA of sufficient quality. During the labelling process, by means of nick translation (that is, cutting DNA and substituting unlabelled nucleotides with digoxigenin, biotin, or fluorochrome labelled nucleotides), DNA becomes even shorter and, in the case of formalin fixed material, the DNA fragments may become too small for optimal CGH experiments. The crosslinking of DNA caused by the fixative can hamper the function of the enzymes, DNA polymerase and DNase, resulting in impaired incorporation of modified nucleotides. This will lead to an irregular and speckled hybridisation pattern of the metaphase chromosomes. As a result, differences in staining intensities between reference and tumour DNA are less pronounced.

Both the standard phenol extraction method $^{192128}$ and commercially available DNA isolation kits, based on affinity columns, can be used and optimised for paraffin wax embedded, formalin fixed tissue. For paraffin wax embedded material in general, a series of $10-20$ sections of $10 \mu \mathrm{m}$ is sufficient to obtain 4-20 $\mu \mathrm{g}$ of DNA, depending on the amount and cellularity of the tissue. To reduce the number of crosslinks between the DNA strands in formalin fixed material, an overnight incubation at $37^{\circ} \mathrm{C}$ with $1 \mathrm{M}$ sodium thiocyanate might be helpful. A prolonged incubation period (three days) with lysis buffer (155 mM $\mathrm{NH}_{4} \mathrm{Cl}, 10 \mathrm{mM} \mathrm{KHCO}, 0.1 \mathrm{mM} \mathrm{Na} \mathrm{N}_{2}$ EDTA, $\mathrm{pH}$ 7.4) and high concentrations of proteinase $\mathrm{K}$ (final concentration $2 \mu \mathrm{g} / \mu \mathrm{l}$, freshly added twice a day) yields a sufficient quantity of relatively good quality DNA from paraffin wax embedded material. A protocol for the extraction of DNA from formalin fixed, paraffin wax embedded tissue, using affinity columns, is given in appendix 1 .

\section{CONTAMINATION}

Contamination (or dilution) of the tumour DNA with normal DNA (for example, from stromal and inflammatory cells) is an undesirable but inevitable problem when analysing tumours. The effect on CGH results will be that the green to red ratio shifts towards 1.0, so 
A

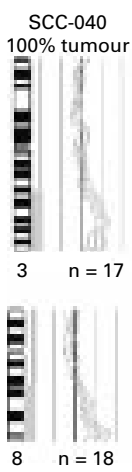

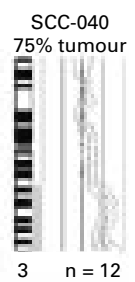

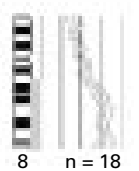

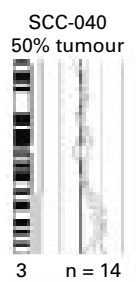

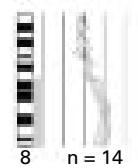

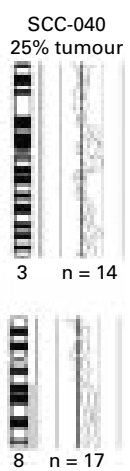

B

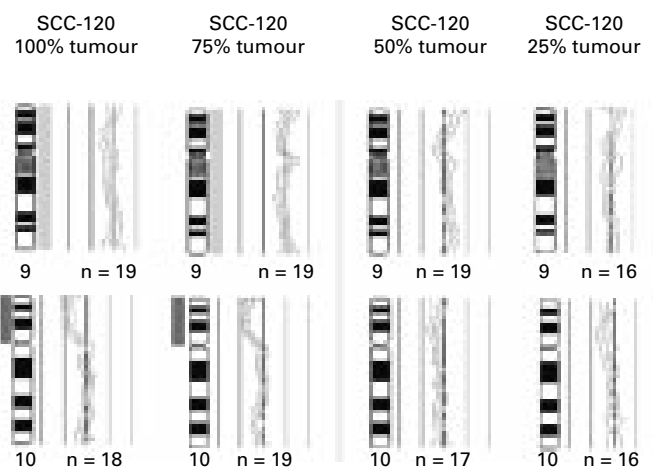

Figure 6 Effect of contamination of tumour DNA with normal DNA on comparative genomic hybridisation (CGH) results. DNA extracted from two tumour cell lines (92-VU040T and 93-VU120T, ${ }^{48}$ referred to hereafter as SCC-040 and $S C C-120$, respectively, was contaminated (mixed) with normal DNA in different concentrations and analysed by CGH. Cell line 1 (SCC-040) is a diploid oral squamous cell carcinoma and cell line 2 (SCC-120) is a triploid oral squamous cell carcinoma. Both cell lines were cytogenetically karyotyped, so most of the genetic aberrations were known. (A) The CGH profiles of certain chromosomes from the diploid tumour; (B) the CGH profiles of certain chromosomes from the triploid tumour. In the triploid tumour, a single copy gain (4:3) or loss (2:3) becomes undetectable at 50\% contamination, whereas in the diploid tumour, a single copy gain (3:2) or loss (1:2) disappears at $75 \%$ contamination. The $95 \%$ confidence interval was used as the threshold.

that if the tumour sample contains too much normal DNA, chromosomal aberrations can go undetected. In a triploid tumour, a single copy gain $(4: 3)$ or loss $(2: 3)$ becomes undetectable at $50 \%$ contamination, whereas in a diploid tumour a single copy gain (3:2) or loss (1:2) disappears at $75 \%$ contamination (fig 6). Therefore, when more than $75 \%$ of the cells are neoplastic, whole sections can be processed. In cases when the tumour content is less than $75 \%$, tumour tissue can be microdissected from the sections by demarcating with a marker, scraping it off with a surgical blade, and collecting it in Eppendorf tubes (fig 7A and $\mathrm{B})$. In addition, advanced laser microdis-
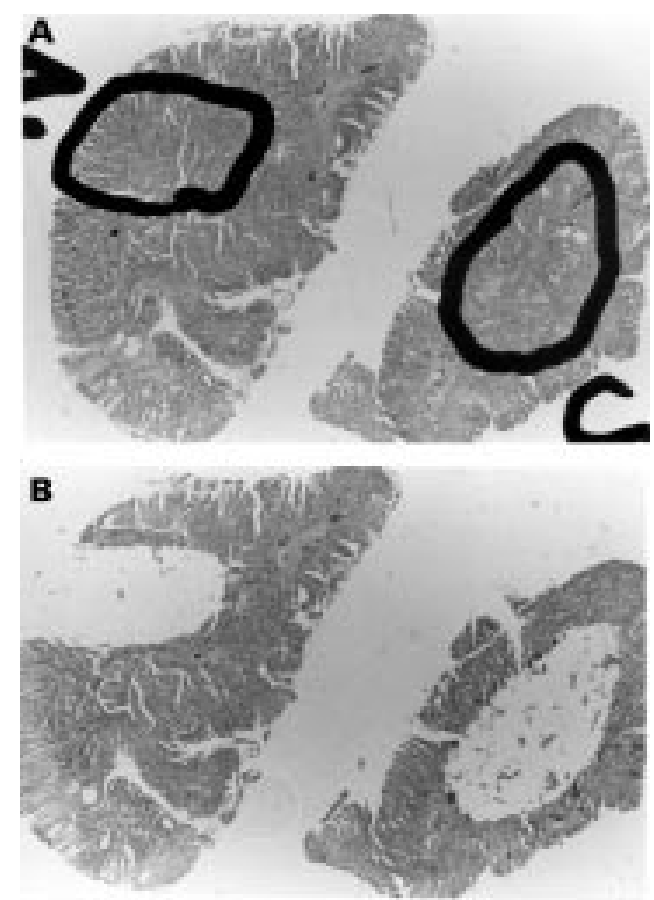

Figure 7 Microdissection of a $10 \mu \mathrm{m}$ tissue section. Example of a $10 \mu \mathrm{m}$ haematoxylin stained tissue section in which most of the tumour cell rich part was demarcated (A) and scraped off with a surgical blade (B). The scraped off tissue from 10-20 such sections is collected in an Eppendorf tube for DNA extraction. section equipment can be used ${ }^{49}$; however, this is expensive and often not necessary. Inflammatory cells are particularly hard to dissect because they have usually infiltrated the tumour. Cell sorting techniques (for example, antibodies attached to magnetic beads or flow cytometric sorting) might permit the selection (and extraction) of tumour cells, or the elimination of inflammatory cells, to produce a more purified tumour DNA sample.

\section{AMOUNT OF DNA}

Approximately $0.5-1 \mu \mathrm{g}$ of DNA is required for one CGH experiment. In the case of carcinomas this is usually not a problem. However, small samples-for example, biopsies from premalignant lesions, might not yield enough DNA. In this situation, DOP-PCR ${ }^{35}$ and other techniques $^{51}$ have been used for DNA amplification. Because of the non-random way in which DOP-PCR may amplify DNA it could give unreliable results. Therefore, additional control experiments (such as a repeated CGH experiment with reverse labelled probes) need to be included in every CGH experiment. In our hands, CGH with DOP-PCR amplified normal DNA hybridised against non-amplified normal DNA yielded CGH profiles with fluorescence ratios smaller or greater than 1.0. When amplifying both test and reference DNA with DOP-PCR, CGH profiles appeared to be more reliable, but not as good as non-amplified normal versus normal DNA (MM Weiss et al, 1998, unpublished results). In conclusion, if enough DNA is available for performing CGH without amplifying the DNA it is preferable not to use DOP-PCR. However, if a lack of sufficient DNA requires amplification, both tumour and reference DNA should be amplified in the same way and control experiments need to be performed simultaneously.

DNA LABELLING

A standard method (nick translation) is used to label the DNA and digest the DNA to the optimal fragment length of 500-1500 bp. A small amount $(0.5-1.0 \mu \mathrm{g})$ of DNA is sufficient. 


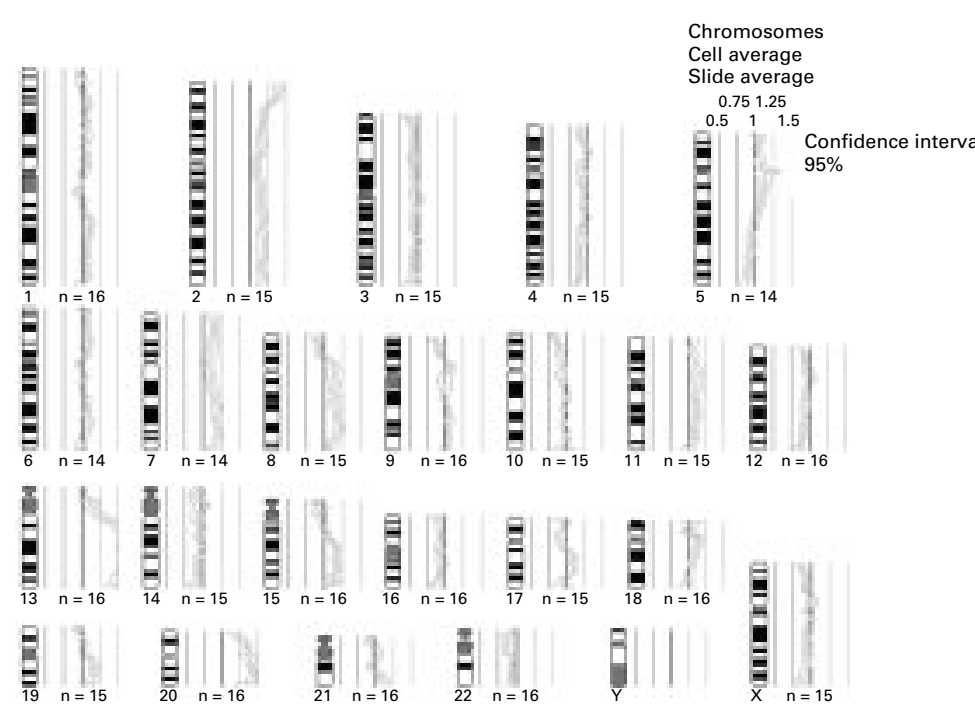

Figure 8 Comparative genomic hybridisation (CGH) analysis profile (stomach carcinoma). Relative copy number karyotype showing the quantitative analysis of a CGH experiment. The mean green to red fluorescence ratios of the chromosomes of multiple metaphases are plotted on a graph corresponding to the chromosome ideograms. With CGH analysis, the highly polymorphic centromeric and heterochromatic regions are excluded for technical reasons. ${ }^{1}$ The relative copy number karyotype in this figure shows clear gains. The most pronounced aberrations are: gains of whole chromosomes 2 and 7, the long arm of chromosome 8, chromosome 13 (high level gain), chromosome 15, the long arm of 19, and chromosome 20. Losses are seen at the tips of the long arms of chromosome 4, 5, and 12.

When biotinylated and digoxigenin conjugated deoxynucleotides (dUTPs) are incorporated into the DNA (indirect labelling) after hybridisation, a detection step with fluorochrome conjugated antibodies (avidin-fluorescein isothiocyanate (FITC) and sheep antidigoxigenin -tetramethyl rhodamine isothiocyanate (TRITC), respectively) is required. Deoxynucleotides that have been directly conjugated with fluorochromes render a smoother but weaker hybridisation signal along the chromosomes. It is important that the labelled DNA fragments of both tumour and reference DNA are in the same range of lengths and are within the limits of $500-1500 \mathrm{bp}$. This has to be checked by electrophoresis on an ethidium bromide stained $1 \%$ agarose gel. A protocol for nick translation is given in appendix 2 .

BLOCKING

Chromosomal regions with short repetitive DNA sequences occur throughout the whole genome, but in a high number at all centromeres, telomeres, and some specific regions (chromosome arms $1 \mathrm{p}$ and $16 \mathrm{p}$, and chromosomes 19 and 22). The lengths of these regions are highly variable between individuals (and thus between tumour and reference DNA), and this can interfere with $\mathrm{CGH}$ analysis. Therefore, repetitive DNA regions are blocked with unlabelled Cot-1 DNA (placental DNA from 50 to $100 \mathrm{bp}$, which is enriched for repetitive DNA sequences). Suboptimal blocking, seen as non-black centromeres, can lead to a reduced amplitude of the green to red ratio (fig 5) and gains and losses may go undetected. As an alternative to blocking, removal of repetitive sequences from the probe may be another solution to this problem. ${ }^{52}$
HYBRIDISATION

Aliquots of $300-350 \mathrm{ng}$ of both tumour and reference labelled DNA (the probes) are mixed with 100 times the same amount of human Cot-1 DNA, precipitated, and resolved in a $6 \mu \mathrm{l}$ hybridisation mix containing $50 \%$ formamide (which decreases the melting temperature of DNA) and $10 \%$ dextran sulphate (which increases the effective probe concentration), in $2 \times$ saline sodium citrate (SSC), $\mathrm{pH}$ 7.0. Sex matching of the normal and the reference labelled DNA is not necessary. In fact, the resulting uneven fluorescence ratio for the $\mathrm{X}$ chromosome could function as an extra control of the quality of the experiment (blocking, strength of the signal). However, sex matching should be taken into account when analysing the X chromosome. The probe and the normal metaphase slides are denatured separately: the slides in $70 \%$ formamide $/ 2 \times \mathrm{SSC}$ at $72^{\circ} \mathrm{C}$ for 5-10 minutes (depending on the metaphase slide batch), and the probes in a water bath at $80^{\circ} \mathrm{C}$ for 10 minutes. The hybridisation takes place under a coverslip in a humid incubator at $40^{\circ} \mathrm{C}$ for two to four days. After hybridisation, the slides are washed and counterstained with DAPI $(0.35 \mu \mathrm{g} / \mathrm{ml}$ in an antifade solution (Vectashield; Vector Laboratories, Burlingame, California, USA) to produce a banding pattern, which enables chromosome identification and karyotyping. A protocol for hybridisation is given in appendix 3.

\section{Hardware and software requirements for CGH}

A detailed description of the hardware and software requirements can be found elsewhere. ${ }^{41}{ }^{43}$ In brief, the analysis of CGH preparations comprises the following steps.

\section{VISUALISATION OF FLUORESCENCE}

Visualisation of fluorescence of a metaphase for DAPI (blue; for chromosome identification), TRITC (red; normal reference DNA), and FITC (green; tumour DNA) using a fluorescence microscope. The microscope, lamp, objective, and the filters require special attention. Mercury arc lamp light sources are adequate if they are stable and can be aligned to give uniform illumination without chromatic variation. Microscope alignment is crucial, and should be given major attention. The objective should be of the "plan" type, apochromatic, and provide $\times 63$ or $\times 100$ magnification, depending on the resolution of the camera (see below). It should transmit UV light, and there should be no lens autofluorescence. The filters used should minimise the crosstalk between the three fluorochromes, which means that narrow band pass filters are required for excitation and emission. However, as the band width of a filter becomes narrower, the brightness of the remaining signals diminishes, which can result in long exposure times. Therefore, filters should provide the best compromise between crosstalk and brightness. Good filter sets for the often used DAPI/TRITC/FITC fluorochrome combination are commercially available. The lateral shift caused during changing between the filters should be 


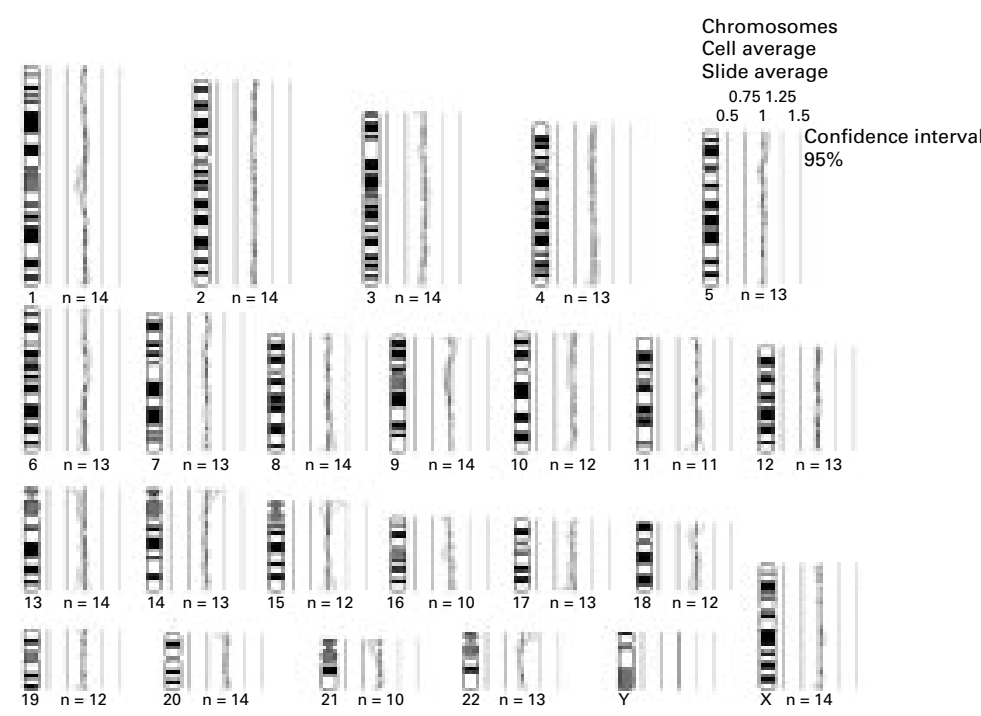

Figure 9 Comparative genomic hybridisation (CGH) control experiment. Relative copy number karyotype of a CGH control experiment (green labelled normal DNA hybridised versus red labelled normal DNA). All the calculated green to red ratios are located close to the 1.0 line.

minimal. An automatic filter wheel could prevent this shift, but software correction is also possible.

RECORDING THE IMAGE

The camera should provide a spatial resolution of $0.1 \mu \mathrm{m}$ at the specimen level, to give an image of $\sim 600 \times 600$ pixels for the average metaphase. It should be capable of integrating the signal for the usual time of five to 10 seconds without generating dark current. An 8 bit photometric resolution is sufficient. The camera should have a good linearity. In practice, most commercially available modern PAL-CCD video cameras will meet these criteria. An expensive camera (such as high resolution or cooled $\mathrm{CCD}$ ) is therefore not necessary for CGH. The computer type is largely determined by the CGH software and can be any UNIX, Macintosh, or Windows 95 based machine with adequate speed. The image capture and storage time for each slide
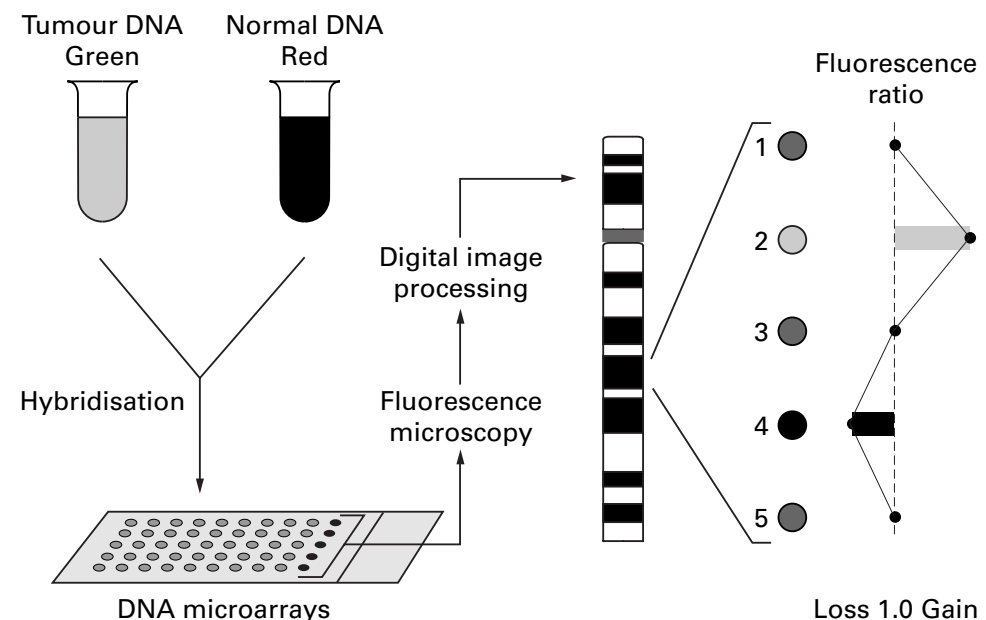

Figure 10 Principle of microarray comparative genomic hybridisation (CGH). Schematic overview of the CGH microarray technique. Tumour and reference DNA are labelled as for "regular" CGH and hybridised to fragments of DNA (instead of metaphase chromosomes) attached to a glass slide, ordered in arrays. Images of the fluorescent signals are captured and the green to red signal ratios are measured digitally for each target.
(10-20 metaphases) is approximately one hour. A high quality colour screen of sufficient size (at least 17 inches) is required for adequate display of the colour images and the graphical user interface of the system. When selecting the metaphases to capture, one should keep in mind the following criteria: hybridisation signals should be strong and homogeneous, not granular; background should be minimal (no residual cytoplasm); there should be minimal overlapping of chromosomes; the chromosomes of all the metaphases should be in the same length range (not extraordinarily long or short). Capturing can be done both automatically or manually in most software programs.

\section{IMAGE PROCESSING}

Dedicated CGH software (Applied Imaging, Newcastle upon Tyne, UK; MetaSystems ISIS, Belmont, Massachusetts, USA; Vysis Inc, Downers Grove, Illinois, USA; PSI PowerGene, League City, Texas, USA; Leica, Cambridge, UK; QCGH Leica, Cambridge, UK) should enable the following steps to be carried out: (1) background subtraction; (2) segmentation and removal of non-chromosome objects; (3) normalisation of the FITC:TRITC ratio for the whole metaphase; (4) interactive karyotyping; and (5) scaling of chromosomes to a standard length, either for the whole chromosome or for each arm of the chromosome independently. For the last option it is necessary to position the centromeres correctly, which is also an interactive feature.

The averaged ratios of several well selected metaphases are plotted along ideograms (showing schematically the G banding patterns) of the corresponding chromosomes in a so called relative copy number karyotype, presenting chromosome areas that are lost (deletions) or gained (amplifications). The interpretation of the ratio profiles can be done using either fixed or statistical thresholds. Fixed limits of 0.75 and 1.25 or 0.85 and 1.15 can be used to identify losses and gains, while others use the $95 \%$ confidence interval (CI) limits of the ratio profile. In the latter, deviations from normal are interpreted as gains or losses when the $95 \%$ CI of the fluorescence ratio does not contain 1.0. Chromosomal regions $1 \mathrm{p} 32-$ pter, $16 \mathrm{p}$, and $19 \mathrm{p}$ should be interpreted with extreme care, and to confirm the CGH findings in these regions, it is recommended that the experiment is repeated with reversed probe labelling. This unreliability is caused by the high amount of repetitive sequences in these regions, which are variable between individuals. The Cot-1 DNA should repress these sequences (see blocking section) but often this approach is only partially successful. Figures 8 and 9 show the result of CGH analysis of tumour (gastric carcinoma) tissue versus normal tissue and of normal tissue versus normal tissue, respectively. In the control experiment, all ratio profiles are around the 1.0 value, whereas in the tumour, deviations can be seen at chromosome arms $2 \mathrm{p}, 2 \mathrm{q}$, $7 \mathrm{p}, 7 \mathrm{q}, 8 \mathrm{q}, 13 \mathrm{q}, 19 \mathrm{q}, 20 \mathrm{p}$, and $20 \mathrm{q}$ (gains) and 4q, 5q, and 12q (losses), using a 95\% CI. 


\section{New developments}

A new technique that is currently being developed in different laboratories is the microarray method. Using metaphase chromosomes for hybridisation limits the detection of events involving small regions $(<10-20 \mathrm{Mb})$ of the genome. The array technique allows the detection of DNA copy number changes (genomic DNA) in more detail, as well as analysing gene expression using cDNA. Most publications so far concern cDNA arrays. ${ }^{53-56}$ Pinkel et al recently published an article on genomic DNA microarrays, ${ }^{57}$ describing a method for the measurement of copy number fluorescence ratios on a set of clones that are located on chromosome 20, with an average interval of $\sim 3 \mathrm{Mb}$. The technique provides a high resolution $( \pm 40 \mathrm{~kb})$ for measurement of gains and losses of DNA sequences in genomes of mammalian complexity (fig 10). Shalon et al hybridised chromosomal probes to arrays of Saccharo- myces cerevisiae genomic DNA fragments. ${ }^{58}$ Microarray CGH will enable the analysis of genetic aberrations in cancer with a high resolution, and will refine the allocation of crucial genes. Moreover, in clinical applications it could enable the identification of the status of certain disease related genes. A detailed discussion can be found elsewhere. ${ }^{59}$

\section{Conclusions}

CGH technology provides genome scale overviews of DNA sequence copy number changes in tumours, using almost any kind of clinical specimen. It maps the origins of amplified and deleted DNA sequences on normal chromosomes, thereby highlighting the locations of important genes. However, to detect translocations, inversions, and small aberrations, additional techniques must be used. Therefore, CGH supplements rather than replaces current methods.

\section{Appendix 1}

DNA isolation protocol for formalin fixed, paraffin wax embedded tissue (10 $\mu$ m sections, haematoxylin stained) based on affinity columns (QIAamp tissue kit; Qiagen, Valencia, California, USA)

(1) If the tissue contains water, spin down for five minutes at maximum speed and decant the supernatant. The next four steps are for unmicrodissected paraffin wax sections only (to remove the wax)

(2) Add $1 \mathrm{ml}$ xylene, incubate for 10 minutes at $55^{\circ} \mathrm{C}$, spin down, and decant supernatant $(\times 3)$.

(3) Add $1 \mathrm{ml}$ methanol, incubate for five minutes at room temperature, spin down, and decant supernatant $(\times 2)$.

(4) Spin down for five minutes and decant the supernatant.

(5) Add $1 \mathrm{ml} 100 \%$ ethanol, vortex, spin down for five minutes, decant the supernatant $(\times 2)$, and air dry the pellet.

(6) Add $1 \mathrm{ml} 1 \mathrm{M} \mathrm{NaSCN}$ and incubate at $37^{\circ} \mathrm{C}$ overnight.

(7) Spin down for five minutes and decant the supernatant.

(8) Add $1 \mathrm{ml}$ phosphate buffered saline (PBS), vortex, spin down, and decant the supernatant $(\times 2)$.

(9) Spin down for five minutes, decant the supernatant, and air dry the pellet.

(10) Add $200 \mu \mathrm{l}$ ATL buffer and $40 \mu \mathrm{l}$ proteinase $\mathrm{K}(10 \mathrm{mg} / \mathrm{ml})$, vortex, and incubate overnight at $55^{\circ} \mathrm{C}$.

(11) Add $40 \mu \mathrm{l}$ proteinase $\mathrm{K}(10 \mathrm{mg} / \mathrm{ml})$ and incubate at $55^{\circ} \mathrm{C}$ all day, vortex approximately every hour during the day.

(12) Add $40 \mu \mathrm{l}$ proteinase $\mathrm{K}(10 \mathrm{mg} / \mathrm{ml})$ at the end of the day, incubate overnight at $55^{\circ} \mathrm{C}$.

(13) Add $40 \mu \mathrm{l} \mathrm{RNase} \mathrm{A}(20 \mathrm{mg} / \mathrm{ml})$, vortex, and incubate for two minutes at room temperature.

(14) Add $400 \mu \mathrm{l}$ AL buffer, vortex, and incubate for 10 minutes at $70^{\circ} \mathrm{C}$.

(15) Add $420 \mu 1100 \%$ ethanol and vortex well.

(16) Place a QIAamp column in a QIAamp tube, apply the total volume of the sample (in steps of maximum $500 \mu \mathrm{l}$ ) on to the column, spin for one minute at $3000 \times g$, decant the filtrate.

(17) Add $500 \mu \mathrm{l}$ AW buffer and spin down for one minute at $8000 \mathrm{rpm}$, decant the filtrate.

(18) Add $500 \mu \mathrm{l}$ AW buffer, spin down for three minutes at maximum speed and decant the filtrate.

(19) Place column into a new Eppendorf tube (not provided)

(20) Elute DNA with $75 \mu \mathrm{AE}$ buffer at $70^{\circ} \mathrm{C}$, incubate for one minute at room temperature, and spin down for one minute at $3000 \times g$.

(21) Measure the DNA concentration the next day.

\section{Appendix 2}

\section{Nick translation for comparative genomic hybridisation (CGH)}

For a $30 \mu$ reaction:

(1) Combine $1 \mu \mathrm{g}$ of probe DNA, $3 \mu \mathrm{l}$ of dNTP reaction mixture $(0.2 \mathrm{mM}$ dATP, dCTP, dGTP; $500 \mathrm{mM}$ Tris/ $\mathrm{HCl}, \mathrm{pH} 7.8 ; 50 \mathrm{mM} \mathrm{MgCl} ; 100 \mu \mathrm{M}$ dithiothreitol; $100 \mu \mathrm{g} / \mathrm{ml}$ bovine serum albumin), $0.5 \mu \mathrm{l}$ of dTTP $(0.2 \mathrm{mM}), 1 \mu \mathrm{l}$ of digoxigenin or biotin conjugated dUTP $(1 \mathrm{ng} / \mu \mathrm{l}), 3 \mu \mathrm{l}$ of DNA polymerase I/DNase I (Gibco BRL, Breda, The Netherlands), 0-1 $\mu$ l diluted DNase I (Gibco BRL). Adjust volume to $30 \mu 1$ with double distilled water. Note, the amount of DNase I added varies for each DNA sample and is dependent upon the DNase I batch (dilute freshly before use).

(2) Incubate for $1.5-2$ hours at $15^{\circ} \mathrm{C}$.

(3) Inactivate enzymes at $70^{\circ} \mathrm{C}$ for 15 minutes.

(4) Check fragment length by gel electrophoresis on an ethidium bromide stained $1 \%$ agarose gel ( $5 \mu \mathrm{l} / \mathrm{sample})$. Run at $100 \mathrm{~V}$ for 30 minutes. Inspect DNA fragment lengths with a UV transilluminator.

(5) For optimum hybridisation conditions, the probe (which is visible as a smear) should be between 500 and $1500 \mathrm{~kb}$ in length. If the probe size is larger, add more DNase I and $3 \mu \mathrm{l}$ DNA polymerase I, incubate at $15^{\circ} \mathrm{C}$ for $15-30$ minutes, and repeat steps 3 and 4 . 


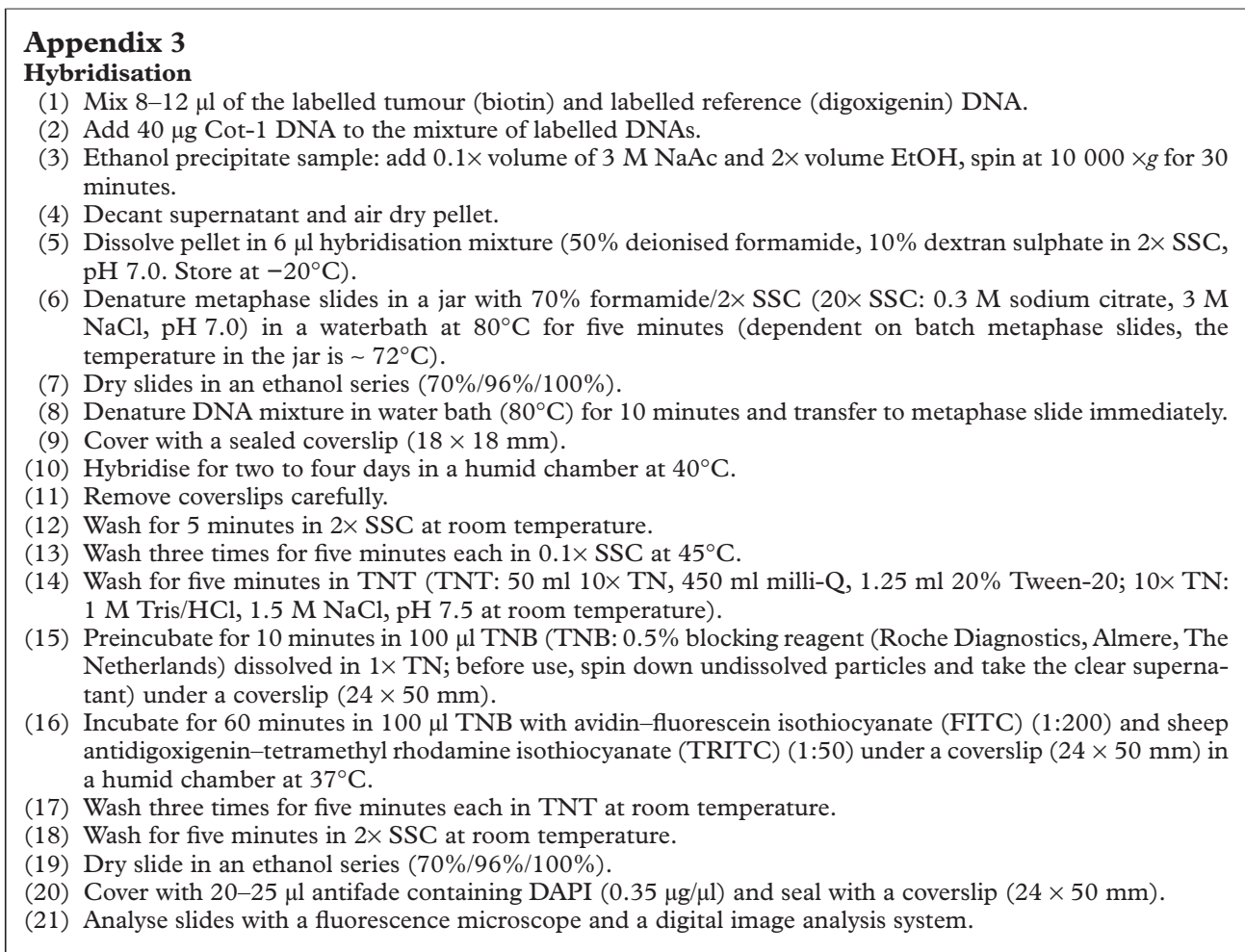

1 Kallioniemi A, Kallioniemi OP, Sudar D, et al. Comparative genomic hybridization for molecular cytogenetic analysis of solid tumors. Science 1992;258:818-21.

2 du Manoir S, Speicher MR, Joos S, et al. Detection of complete and partial chromosome gains and losses by comparative genomic hybridization. Hum Genet 1993;90: 590-610.

3 Torenbeek R, Hermsen MAJA, Meijer GA, et al. Analysis by comparative genomic hybridisation of epithelial and
spindle cell components in sarcomatoid carcinoma and spindle cell components in sarcomatoid carcinoma and
carcinosarcoma. Histogenetic aspects. F Pathol [In press.]

4 Kallioniemi OP, Kallioniemi A, Piper J, et al. Optimizing comparative genomic hybridization for analysis of DNA sequence copy number changes in solid tumors. Genes Chromosomes Cancer 1994;10:231-43.

5 Monni O, Oinonen R, Elonen E, et al. Gain of 3q and deletion of $11 \mathrm{q} 22$ are frequent aberrations in mantle cell lymphoma. Genes Chromosomes Cancer 1998;21:298-307.

6 Bentz M, Dohner H, Huck K, et al. Comparative genomic Bentz M, Dohner $\mathrm{H}$, Huck K, et al. Comparative genomic
hybridization in the investigation of myeloid leukemias. hybridization in the investigation of myeloi
Genes Chromosomes Cancer 1995;12:193-200.

7 Hermsen MAJA, Baak JPA, Meijer GA, et al. Genetic analysis of 53 lymph node-negative breast carcinomas by CGH and relation to clinical, pathological, morphometric, and DNA cytometric prognostic factors. F Pathol 1998;186: 356-62.

8 Meijer GA, Hermsen MAJA, Baak JPA, et al. Progression from colorectal adenoma to carcinoma is associated with non-random chromosomal gains as detected by comparanon-random chromosomal gains as detected by compar

9 Riopel MA, Spellerberg A, Griffin CA, et al. Genetic analyRiopel MA, Spellerberg A, Griffin CA, et al. Genetic analy-
sis of ovarian germ cell tumors by comparative genomic sis of ovarian germ cell tumors by comparati
hybridization. Cancer Res 1998;58:3105-10.

10 Tarkkanen M, Bohling T, Gamberi G, et al. Comparative genomic hybridization of low-grade central osteosarcoma Mod Pathol 1998;11:421-6.

11 Ried T, Knutzen R, Steinbeck R, et al. Comparative genomic hybridization reveals a specific pattern of chromosomal gains and losses during the genesis of colorectal tumors. Genes Chromosomes Cancer 1996;15:234-45.

12 Weber RG, Scheer M, Born IA, et al. Recurrent chromosomal imbalances detected in biopsy material from oral premalignant and malignant lesions by combined tissue
microdissection, universal DNA amplification, and commicrodissection, universal DNA amplification, and comparative gen
$295-303$.

13 Tirkkonen M, Tanner M, Karhu R, et al. Molecular cytogenetics of primary breast cancer by CGH. Genes Chromosomes Cancer 1998;21:177-84.

14 Nupponen NN, Kakkola L, Koivisto P, et al. Genetic alterations in hormone-refractory recurrent prostate carcinomas. Am f Pathol 1998;153:141-8.

15 Taguchi T, Cheng GZ, Bell DW, et al. Combined chromosome microdissection and comparative genomic hybridization detect multiple sites of amplification DNA in a human lung carcinoma cell line. Genes Chromosomes Cancer 1997;20:208-12.

16 Weber RG, Sommer C, Albert FK, et al. Clinically distinct subgroups of glioblastoma multiforme studied by comparative genomic hybridization. Lab Invest 1996;74:10819.

17 Bastian BC, LeBoit PE, Hamm H, et al. Chromosomal gains and losses in primary cutaneous melanomas detected by and losses in primary cutaneous melanomas detected by 2170-5.

18 Szymanska J, Virolainen M, Tarkkanen M, et al. Overrepresentation of 1q21-23 and 12q13-21 in lipoma-like liposarcomas but not in benign lipomas: a comparative genomic hybridization study. Cancer Genet Cytogenet 1997;99:14-18.

19 Simon R, Burger H, Brinkschmidt C, et al. Chromosomal aberrations associated with invasion in papillary superficial bladder cancer. F Pathol 1998;185:345-51.

20 Tienari J, Reima I, Larramendy ML, et al. A cloned human germ cell tumor-derived cell line differentiating in culture. Int 7 Cancer 1998;77:710-19.

21 Isola JJ, Kallioniemi OP, Chu LW, et al. Genetic aberrations detected by comparative genomic hybridization predict outcome in node-negative breast cancer. Am F Pathol 1995; 147:905-11.

22 Daniely M, Aviram-Goldring A, Barkai G, et al. Detection of chromosomal aberration in fetuses arising from recurrent spontaneous abortion by comparative genomic hybridization. Hum Reprod 1998;13:805-9.

23 Yu LC, Moore DH, 2nd, Magrane G, et al. Objective aneuploidy detection for fetal and neonatal screening using comparative genomic hybridization (CGH). Cytometry 1997;28:191-7.

24 Wang BB, Yu LC, Peng W, et al. Prenatal identification of $\mathrm{i}(\mathrm{Yp})$ by molecular cytogenetic analysis. Prenat Diagn 1995;15:1115-19.

25 Knuutila S, Bjorkqvist AM, Autio K, et al. DNA copy number amplifications in human neoplasms: review of comparative genomic hybridization studies. Am f Pathol 1998;152:1107-23.

26 Forozan F, Karhu R, Kononen J, et al. Genome screening by comparative genomic hybridization. Trends Genet 1997;13: 405-9.

27 Hermsen MA, Meijer GA, Baak JP, et al. Comparative genomic hybridization: a new tool in cancer pathology. Hum Pathol 1996;27:342-9.

28 Lapierre JM, Cacheux V, Da Silva F, et al. Comparative genomic hybridization: technical development and cytogenetic aspects for routine use in clinical laboratories. Ann Genet 1998;41:56-62.

29 Larramendy ML, El-Rifai W, Knuutila S. Comparison of fluorescein isothiocyanate- and Texas red-conjugated nucleotides for direct labeling in comparative genomic hybridization. Cytometry 1998;31:174-9.

30 Kirchhoff $M$, Gerdes T, Rose H, et al. Detection of chromosomal gains and losses in comparative genomic hybridization 
analysis based on standard reference intervals. Cytometry 1998:31:163-73.

31 Kirchhoff $M$, Gerdes T, Rose H, et al. Detection of chromosomal gains and losses in comparative genomic hybridization analysis based on standard reference intervals Cytometry 1998;31:163-73.

32 Bentz M, Plesch A, Stilgenbauer S, et al. Minimal sizes of deletions detected by comparative genomic hybridization. Genes Chromosomes Cancer 1998;21:172-5.

33 el-Rifai W, Larramendy ML, Bjorkqvist AM, et al. Optimization of comparative genomic hybridization using fluorochrome conjugated to dCTP and dUTP nucleotides. $L a b$ Invest 1997;77:699-700

34 Knuutila S, Armengol G, Bjorkqvist AM, et al. Comparative genomic hybridization study on pooled DNAs from tumors of one clinical-pathological entity. Cancer Genet Cytogenet 1998;100:25-30.

35 Kuukasjarvi T, Tanner M, Pennanen S, et al. Optimizing DOP-PCR for universal amplification of small DNA samples in comparative genomic hybridization. Genes Chromoples in comparative genomic hy
somes Cancer 1997;18:94-101.

36 Karhu R, Kahkonen M, Kuukasjarvi T, et al. Quality control of CGH: impact of metaphase chromosomes and the dynamic range of hybridization. Cytometry 1997;28:198 205

37 Moore DH 2nd, Pallavicini M, Cher ML, et al. A t-statistic for objective interpretation of comparative genomic hybridization (CGH) profiles. Cytometry 1997;28:183-90.

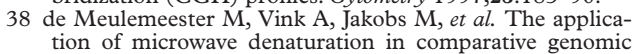
hybridization. Genet Anal 1996;13:129-33.

39 Tirkkonen M, Karhu R, Kallioniemi O, et al. Evaluation of camera requirements for comparative genomic hybridization. Cytometry 1996;25:394-8.

40 Lundsteen C, Maahr J, Christensen B, et al. Image analysis in comparative genomic hybridization. Cytometry 1995;19: 42-50.

41 du Manoir S, Kallioniemi OP, Lichter P, et al. Hardware and software requirements for quantitative analysis of comparasoftware requirements for quantitative analysis of co
tive genomic hybridization. Cytometry 1995;19:4-9.

42 du Manoir S, Schrock E, Bentz M, et al. Quantitative analysis of comparative genomic hybridization. Cytometry 1995; 19:27-41.

43 Piper J, Rutovitz D, Sudar D, et al. Computer image analysis of comparative genomic hybridization. Cytometry 1995;19: $10-26$

44 Liang BC, Meltzer PS, Guan XY, et al. Gene amplification elucidated by combined chromosomal microdissection and comparative genomic hybridization. Cancer Genet Cytogenet 1995;80:55-9.

45 Kallioniemi OP, Kallioniemi A, Sudar D, et al. Comparative genomic hybridization: a rapid new method for detecting and mapping DNA amplification in tumors. Semin Cancer 1993;4:41-6.

46 Joos S, Scherthan H, Speicher MR, et al. Detection of amplified DNA sequences by reverse chromosome painting using genomic tumor as probe. Hum Genet 1993;90:54889

47 Bentz M, Huck K, du Manoir S, et al. Comparative genomic hybridization in chronic B-cell leukemias shows a high incidence of chromosomal gains and losses. Blood 1995;85: 3610-18.

48 Hermsen MAJA, Joenje $\mathrm{H}$, Arwert F, et al. Centromeric breakage as a major cause of cytogenetic abnormalities in oral squamous cell carcinoma. Genes Chromosomes Cancer 1996;15:1-9.

49 Zitzelsberger H, Kulka U, Lehmann L, et al. Genetic heterogeneity in a prostatic carcinoma and associated prostatic intraepithelial neoplasia as demonstrated by combined use of laser-microdissection, degenerate oligonucleotide primed PCR and comparative genomic hybridization. Virchows Arch 1998;433:297-304.

50 Telenius H, Carter NP, Bebb CE, et al. Degenerate oligonucleotide-primed PCR: general amplification of target DNA by a single degenerate primer. Genomics 1992; 13:718-25.

51 Lucito R, Nakimura M, West JA, et al. Genetic analysis using genomic representations. Proc Natl Acad Sci USA 1998;95:4487-92.

52 Craig JM, Kraus J, Cremer T. Removal of repetitive sequences from FISH probes using PCR-assisted affinity chromatography. Hum Genet 1997;100:472-6.

53 Schena M, Shalon D, Davis RW, et al. Quantitative monitoring of gene expression patterns with a complementary DNA microarray. Science 1995;270:467-70.

54 Schena M, Shalon D, Heller R, et al. Parallel human genome analysis: microarray-based expression monitoring of 1000 genes. Proc Natl Acad Sci USA 1996;93:10614-19.

55 Schena $M$. Genome analysis with gene expression microarrays. Bioessays 1996;18:427-31.

56 Heller RA, Schena M, Chai A, et al. Discovery and analysis Heller RA, Schena M, Chai A, et al. Discovery and analysis of inflamm. Proc Natl Acad Sci USA 1997;94:2150-5.

57 Pinkel D, Segraves R, Sudar D, et al. High resolution analysis of DNA copy number variation using comparative genomic hybridization to microarrays. Nat Genet 1998;20: 207-11

58 Shalon D, Smith SJ, Brown PO. A DNA microarray system for analyzing complex DNA samples using two-color fluorescent probe hybridization. Genome Res 1996;6:639-45.

59 Collins FS, Lander ES, Southern E, et al. The chipping forecast. Nat Genet 1999;21:1-60. 